\title{
Acyl-CoA : dihydroxyacetone phosphate acyltransferase in human skin fibroblasts: study of its properties using a new assay method
}

\author{
Ruud B.H. Schutgens ${ }^{\text {a }}$, Gerrit-Jan Romeyn ${ }^{\text {a }}$, Rob Ofman ${ }^{\text {a }}$, \\ Henk van den Bosch ${ }^{b}$, Joseph M. Tager ${ }^{c}$ and Ronald J.A. Wanders ${ }^{a}$ \\ ' Department of Pediatrics, University' Hospital Amsterdam, AMC, Meibergdreef 9, 1105 AZ Amsterdam \\ (The Netherlands), "Department of Biochemistry, State University of Utrech, Padualaan 8, Utrecht, $3584 \mathrm{CH}$ Utrecht \\ (The Netherlands) and "Department of Biochemistry, University' of Amsterdam, Meibergdreef 15, 1105 AZ Amsterdam \\ (The Netherlands)
}

(Received 18 July 1986)

Key words: Acyl transferase; Etherphospholipid; Plasmalogen; Peroxisome; Zellweger syndrome; (Human skin fibroblast)

In relation to the finding that human skin fibroblasts are capable of de novo ether phospholipid biosynthesis, we have studied the properties of acyl-CoA:dihydroxyacetone phosphate acyltransferase in fibroblast homogenates using a new assay method. The results indicate that the acylation of dihydroxyacetone phosphate shows an optimum at $\mathrm{pH} 5.5$ with a broad shoulder of activity up to $\mathrm{pH} 6.4$ and a decline in activity up to $\mathrm{pH}$ 8.2. At pH 5.5 the acyltransferase accepts dihydroxyacetone phosphate, but not glycerol 3-phosphate as a substrate. Furthermore, the transferase activity was found to be membrane-bound and inactivated by Triton X-100 at concentrations above $0.025 \%(w / v)$. Similar properties have been described for the enzyme as present in rat-liver and guinea-pig liver peroxisomes. These data, together with the finding that acyl-CoA:dihydroxyacetone phosphate acyltransferase is deficient in cultured skin fibroblasts from patients without peroxisomes (Zellweger syndrome), suggest that in cultured skin fibroblasts the enzyme is primarily located in peroxisomes.

\section{Introduction}

Ether glycerophospholipids are found in nearly all animal and bacterial cells with the exception of most aerobic bacteria (for reviews see Refs. 1 and 2). Alkyl-acyl glycerophospholipids contain a hydrocarbon chain attached to the $\mathrm{C}-1$ of the glycerol backbone via an ether linkage, whereas in plasmalogens the linkage is via a dehydrated hemia-

Abbreviation: DHAP, dihydroxyacetone phosphate.

Correspondence: Dr. Ruud B.H. Schutgens, Department of Pediatrics, University Hospital Amsterdam, AMC, Meibergdreef 9, $1105 \mathrm{AZ}$ Amsterdam, The Netherlands. cetal (vinyl ether). The discovery in recent years of the very potent effects of 1-alkyl-2-acetyl-snglycerol-3-phosphocholine (platelet-activating factor) emphasizes the importance of ether phospholipids. However, much has still to be learned about the distinctive properties and physiological importance of ether lipids.

Mainly through the work from the groups of Hajra and Snyder (for reviews see Refs. 3-5) it has been established that the enzyme alkyl dihydroxyacetone phosphate synthase is responsible for the introduction of the characteristic ether bond in ether phospholipids. The reaction involves the displacement of the fatty acyl group in acyl dihydroxyacetone phosphate (acyl DHAP) by a 
long-chain alcohol to form 1-O-alkyl dihydroxyacetone phosphate (alkyl DHAP). Since alkyl DHAP synthase accepts acyl dihydroxyacetone phosphate but not acyl glycerol 3-phosphate as a substrate [6], acyl DHAP is obligatory for the synthesis of ether lipids in higher organisms. Acyl DHAP can be synthesized directly via the enzymatic acylation of DHAP with acyl-CoA. In initial studies the enzyme catalyzing this reaction, acyl-CoA : dihydroxyacetone phosphate acyltransferase, was found to be localized in mitochondrial and microsomal fractions in different tissues (for reviews see Refs. 3-5). However, more detailed investigations into the subcellular localization of acyl-CoA : dihydroxyacetone phosphate acyltransferase have shown that the enzyme is primarily located in peroxisomes in different mammalian tissues [7-12].

Cultured human skin fibroblasts, like other cell types [13], are capable of de novo ether phospholipid biosynthesis [14]. In order to obtain further information on the role of the acyl DHAP pathway in cellular ether phospholipid synthesis, we have studied the properties of acyl-CoA : dihydroxyacetone phosphate acyltransferase as present in cultured skin fibroblasts. Here we describe the characteristics of this enzyme activity using a simple assay system not requiring the prior synthesis of dihydroxyacetone $\left[{ }^{32} \mathrm{P}\right]$ phosphate. Instead radiolabelled dihydroxyacetone phosphate is synthesized in situ enzymically for commercially available $\left[{ }^{14} \mathrm{C}\right]$ glycerol 3-phosphate.

\section{Materials and Methods}

Acyl-CoA:dihydroxyacetone phosphate acyltransferase assay

$\left[\mathrm{U}_{-}{ }^{14} \mathrm{C}\right]$ Dihydroxyacetone phosphate was prepared from L-[U-14 C]glycerol 3-phosphate in a medium containing $50 \mathrm{mM}$ triethanolamine- $\mathrm{HCl}$ (pH 7.6), $0.6 \mathrm{mM} \mathrm{L-[U-14}$ C]glycerol 3-phosphate $(10 \mu \mathrm{Ci}), 5 \mathrm{mM}$ pyruvate, $1 \mathrm{mM} \mathrm{NAD}{ }^{+}, 10$ units of lactate dehydrogenase and 10 units of glycerol3-phosphate dehydrogenase in a total volume of $1.0 \mathrm{ml}$. Reactions were carried out at $25^{\circ} \mathrm{C}$ for 60 min. Reactions were terminated by addition of an equal volume of chloroform and the resulting suspension was mixed vigorously on a vortex apparatus for $5 \mathrm{~min}$. The upper layer containing the radiolabelled dihydroxyacetone phosphate was collected by centrifugation. A $20 \mu 1$ aliquot was used in a standard acyl-CoA:dihydroxyacetone phosphate acyltransferase assay containing the following components: $75 \mathrm{mM}$ sodium acetate buffer ( $\mathrm{pH}$ 5.4), $8 \mathrm{mM}$ sodium fluoride, $8 \mathrm{mM}$ $\mathrm{MgCl}_{2}, 0.4 \mathrm{mg}$ bovine serum albumin, $0.15 \mathrm{mM}$ palmitoyl-CoA, $0.1 \mathrm{mM}\left[\mathrm{U}-{ }^{14} \mathrm{C}\right.$ ]dihydroxyacetone phosphate and 20-70 $\mu \mathrm{g}$ fibroblast protein homogenate in a total volume of $0.12 \mathrm{ml}$. Incubations were carried out at $37^{\circ} \mathrm{C}$ and reactions terminated as described [15].

\section{Preparation of fibroblast homogenates}

Fibroblasts were cultured according to standard procedures and stored at $-70^{\circ} \mathrm{C}$ until use. Fibroblasts were suspended in a medium containing $50 \mathrm{mM} \mathrm{NaCl}$ and $5 \mathrm{mM}$ Tris- $\mathrm{HCl}$ (final $\mathrm{pH}$ 7.5 ) and sonicated at $80 \mathrm{~W}$ for three 15 -s periods with 45-s intervals cooling; this was followed by three cycles of freezing in liquid nitrogen and thawing.

\section{Materials}

L- $\left[\mathrm{U}-{ }^{14} \mathrm{C}\right]$ Glycerol 3-phosphate was obtained from the Radiochemical Centre, Amersham, U.K. Palmitoyl-CoA and fatty acid-free bovine serum albumin were from Sigma, St. Louis, U.S.A. Nucleotides and enzymes were from Boehringer, Mannheim, F.R.G. All other reagents were of analytical grade.

\section{Results}

Characteristics of the acyl-CoA:dihydroxyacetone phosphate acyltransferase assay system

Experimental determination of acyl-CoA : dihydroxyacetone phosphate acyltransferase is complicated by the fact that radiolabelled dihydroxyacetone phosphate is not commercially available. In the original procedure described by Hajra [16] (see also Ref. 17) ${ }^{32}$ P-labelled dihydroxyacetone phosphate is synthesized via enzymatic phosphorylation of dihydroxyacetone using $\left[\gamma^{32} \mathrm{P}\right]-$ ATP, followed by purification of the dihydroxyacetone $\left[{ }^{32} \mathrm{P}\right]$ phosphate. In order to circumvent this laborious and complicated procedure Dodds et al. [18] developed an alternative procedure in which radiolabelled palmitoyl-CoA is used rather 
than radiolabelled dihydroxyacetone phosphate. However, this method suffers from a similar disadvantage, since the acyl dihydroxyacetone phosphate synthesized has to be isolated by thin-layer chromatography. Bates and Saggerson [19] have described a procedure in which dihydroxyacetone phosphate is generated in situ from commercially available [U- ${ }^{14} \mathrm{C}$ ]fructose 1,6 -bisphosphate using aldolase and triose-phosphate isomerase. The assay system we have developed is also based on the principle of in situ synthesis of radiolabelled dihydroxyacetone phosphate. This is done by enzymic conversion of $\left[{ }^{14} \mathrm{C}\right]$ glycerol 3-phosphate, which is commercially available, into $\left[{ }^{14} \mathrm{C}\right]$ dihydroxyacetone phosphate using glycerol-3-phosphate dehydrogenase. Since the equilibrium position of the glycerol-3-phosphate dehydrogenase reaction is strongly towards glycerol 3-phosphate formation, pyruvate $(5 \mathrm{mM})$ and lactate dehydrogenase were added in order to shift the overall reaction towards dihydroxyacetone phosphate formation.

Fig. 1 shows that under such conditions there is a virtually complete conversion of glycerol 3-phosphate into dihydroxyacetone phosphate with the

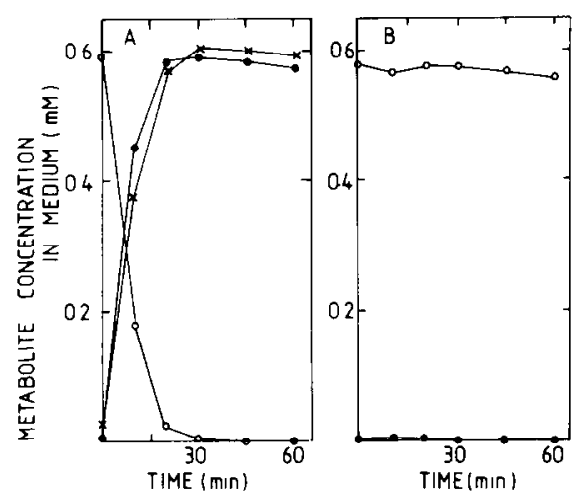

Fig. 1. Dihydroxyacetonephosphate generation from glycerol 3-phosphate. L-Glycerol 3-phosphate $(0.6 \mathrm{mM})$ was added to a medium containing $50 \mathrm{mM}$ triethanolamine- $\mathrm{HCl}(\mathrm{pH} \mathrm{7.6)}$ and $1 \mathrm{mM} \mathrm{NAD}^{+}$. In the experiment of $A$, but not in $B, 5 \mathrm{mM}$ pyruvate plus 10 units lactate dehydrogenase were added as well. Reactions were started by addition of 10 units glycerol-3phosphate dehydrogenase. At the indicated time points reactions were terminated via addition of perchloric acid $3.5 \%$ $(w / v)$ final concentration). After centrifugation and neutralization with $2 \mathrm{M} \mathrm{KOH} / 0.3 \mathrm{M}$ morpholinepropanesulphonic acid, lactate $(X)$, glycerol 3-phosphate $(O)$ and dihydroxyacetone phosphate (๑) were determined in the neutralized extracts essentially as described in Ref. 11 . concomitant stoichiometric production of both lactate and dihydroxyacetone phosphate. When the $\mathrm{NAD}^{+}$-regenerating system consisting of pyruvate plus lactate dehydrogenase was omitted from the medium, almost no dihydroxyacetone phosphate was formed (Fig. 1B). Based on these results $\left[{ }^{14} \mathrm{C}\right]$ dihydroxyacetone phosphate was generated enzymatically from $\left[{ }^{14} \mathrm{C}\right]$ glycerol 3 -phosphate as described in Fig. 1 and used in the acyl-CoA : dihydroxyacetone phosphate acyltransferase assay (for full details see Materials and Methods).

Properties of acyl-CoA : dihydroxyacetone phosphate acyltransferase in homogenates of cultured human skin fibroblasts

The results in Fig. 2A indicate that the rate of dihydroxyacetone phosphate acylation, when measured under the standard conditions described in Materials and Methods, gradually declines in time. The activity of the enzyme, measured as the amount of product formed in $2 \mathrm{~h}$, is linear with the amount of protein at least up to concentrations of $600 \mu \mathrm{g} / \mathrm{ml}$ (Fig. 2B). The gradual decline in the rate of acylation in time seen in Fig. 2A must be due to a slow inactivation of the enzyme. However, a reaction time of $120 \mathrm{~min}$ was chosen in order to increase the sensitivity of the assay.

The acylation of dihydroxyacetone phosphate in homogenates of skin fibroblasts was found to be optimal at $\mathrm{pH} 5.5$ with a broad shoulder of activity up to a $\mathrm{pH}$ of 6.4 and a decline in activity

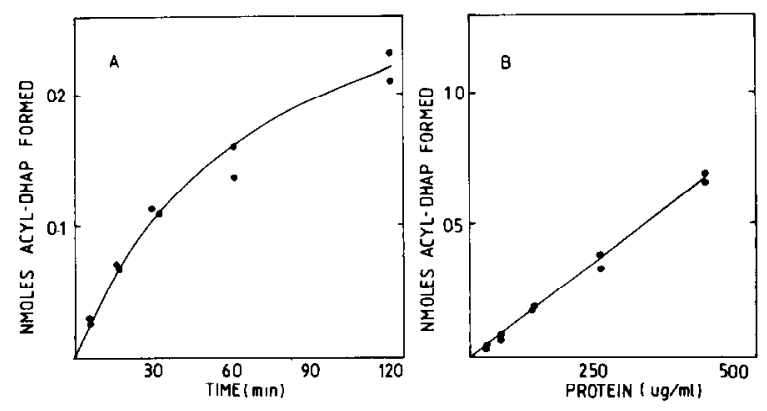

Fig. 2. Acyl-CoA: dihydroxyacetone phosphate acyltransferase activity in human skin fibroblasts as a function of time and protein concentration. Incubations were carried out as described in Materials and Methods. The amount of homogenate proteins used in the experiment in $A$ was $200 \mu \mathrm{g} / \mathrm{ml}$ and the time of incubation in the experiment in $\mathrm{B}$ was $120 \mathrm{~min}$. 
up to $\mathrm{pH} 8.2$ (Fig. 3). Similar pH-versus-activity profiles have been described for acyl-CoA : dihydroxyacetone phosphate acyltransferase as present in peroxisomes from guinea-pig liver [9] and rat liver [11]. When glycerol-3-phosphate acyltransferase was assayed under the conditions of Fig. 3, activity was found to be optimal at $\mathrm{pH} 7.4$ with no activity at pH 5.5 (Fig. 3).

Kinetic properties of the acyl-CoA : dihydroxyacetone phosphate acyltransferase reaction

Fig. 4 shows the dependence of the enzyme activity on the concentration of dihydroxyacetone phosphate. The apparent $K_{\mathrm{m}}$ for the enzyme in control fibroblasts as deduced from the double-reciprocal plot was $140 \mu \mathrm{M}$.

The kinetic properties of the acyl-CoA:dihydroxyacetone phosphate acyltransferase reaction were also studied with regard to palmitoyl-CoA. At a fixed molar ratio of hovine serum albumin to palmitoyl-CoA of $1: 3$ half-maximal activity was reached at a total concentration of the CoA ester of $0.03 \mathrm{mM}$ (not shown).

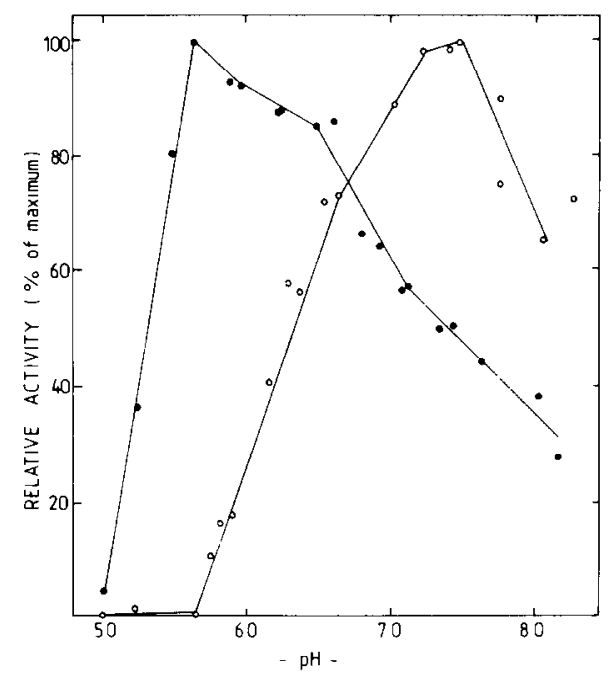

Fig. 3. Effect of $\mathrm{pH}$ on the acyl-CoA : dihydroxyacetone phosphate acyltransferase and acyl-CoA: glycerol 3-phosphate acyltransferase activity in human skin fibroblasts. Assays were performed under standard conditions as described in Materials and Methods in buffers containing $50 \mathrm{mM}$ sodium acetate $(\mathrm{pH}$ 5.0-5.85), $50 \mathrm{mM}$ Mes- $\mathrm{NaOH}$ (pH 5.77-6.58), $50 \mathrm{mM}$ Mops$\mathrm{NaOH}(\mathrm{pH} 6.60-7.41)$ and Tris- $\mathrm{HCl}(\mathrm{pH} \mathrm{7.50-8.20).}$ CoA: dihydroxyacetonephosphate acyltransferase; $O$, acylCoA: glycerol 3-phosphate acyltransferase (G3PAT).

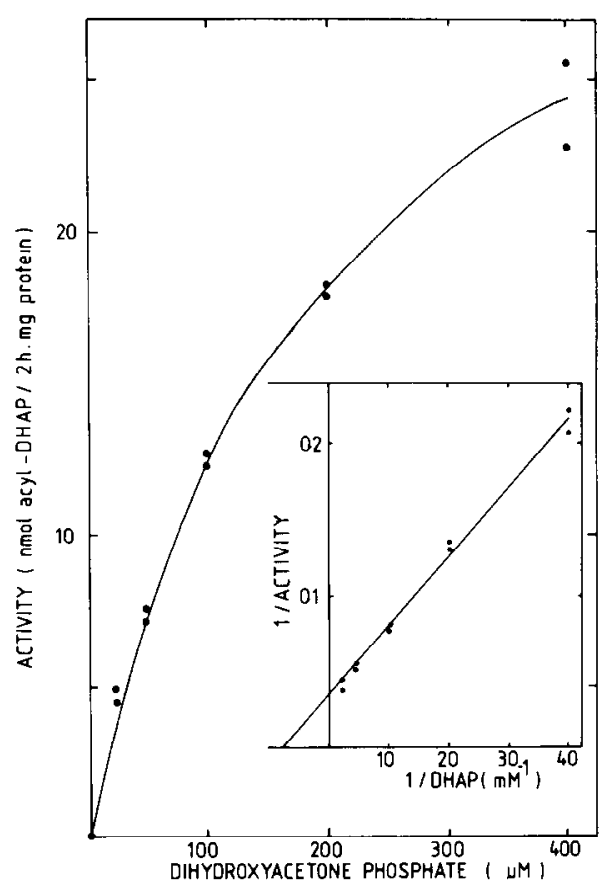

Fig. 4. Acyl-CoA : dihydroxyacetone phosphate acyltransferase activity in human skin fibroblasts as a function of the concentration of dihydroxyacetone phosphate (DHAP). Incubations were carried out as described in Materials and Methods except that the concentration of dihydroxyacetone phosphate (DHAP) was varied as indicated. Time of incubation $120 \mathrm{~min}$.

Effect of glycerol 3-phosphate and Triton X-100 on the acylation of dihydroxyacetone phosphate at $\mathrm{pH}$ 5.5

Fig. 5A shows that the acylation of dihydroxyacetone phosphate at $\mathrm{pH} 5.5$ is not inhibited significantly by glycerol 3-phosphate at concentrations up to $10 \mathrm{mM}$. Acyl-CoA : dihydroxyacetone phosphate acyltransferase in rat brain peroxisomes [17], guinea-pig liver peroxisomes [9] and rat liver peroxisomes [11] showed identical behaviour.

Fig. 5B shows that the acylation of dihydroxyacetone phosphate was stimulated about $20 \%$ by Triton X-100 in concentrations up to $0.01 \%(\mathrm{w} / \mathrm{v})$, whereas higher concentrations became inhibitory. In order to investigate whether acyl-CoA:dihydroxyacetone phosphate acyltransferase is membrane-bound, as reported for the rat liver and guinea-pig liver enzyme [9,11], or not, fibroblasts were sonicated and separated in a soluble fraction 

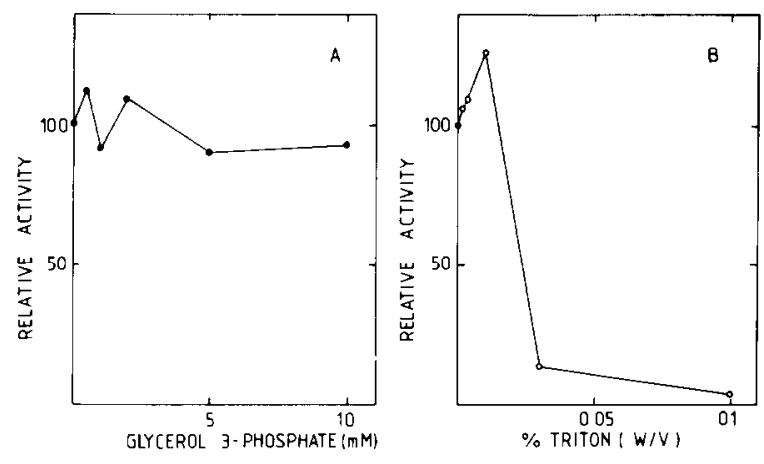

Fig. 5. Effect of glycerol 3-phosphate and Triton X-100 on the acyl-CoA: dihydroxyacetone phosphate acyltransferase activity in human skin fibroblasts. The assays were performed as described in Materials and Methods with variable glycerol 3-phosphate (A) and Triton X-100 (B) concentrations as indicated. Time of incubation, $120 \mathrm{~min}$. Protein concentration: 140 $\mu \mathrm{g} / \mathrm{ml}(\mathrm{A})$ and $112 \mu \mathrm{g} / \mathrm{ml}(\mathrm{B})$.

and a membrane fraction via high-speed centrifugation. $\left(120000 \times \mathrm{g}, 30 \mathrm{~min}, 4^{\circ} \mathrm{C}\right)$. Acyl-CoA : dihydroxyacetone phosphate acyltransferase was found to be associated with the membrane fraction, whereas the bulk of catalase activity was found in the soluble fraction (not shown).

\section{Discussion}

It has become clear in recent years that acylCoA : dihydroxyacetone phosphate acyltransferase and alkyl dihydroxyacetone phosphate synthase are localized primarily in peroxisomes of rodent liver and brain (for reviews see Refs. 5 and 10). The properties of acyl-CoA: dihydroxyacetone phosphate acyltransferase were studied by Jones and Hajra [9] in guinea-pig liver peroxisomes and found to differ markedly from those of microsomal glycerol-3-phosphate acyltransferase. The peroxisomal acyltransferase showed an optimal $\mathrm{pH}$ at 5.5 , was not inhibited by $N$-ethylmaleimide and accepted dihydroxyacetone phosphate but not glycerol 3-phosphate as a substrate [9]. Similar results have been obtained by De Clerq et al. [11] for the rat liver peroxisomal enzyme.

The results presented in this paper show that human fibroblasts contain an appreciable acylCoA : dihydroxyacetone phosphate acyltransferase activity. This activity is comparable to the activity found in human liver and brain [15]. Fig. 3 indicates that the acylation of dihydroxyacetone phosphate shows an optimum at pH 5.5 with a broad shoulder of activity between 5.5 and 6.4, which closely corresponds to the findings of Jones and Hajra [9] and De Clerq et al. [11] regarding the enzyme in guinea-pig liver and rat liver peroxisomes, respectively. The acylation of dihydroxyacetone phosphate in homogenates of human skin fibroblasts is not inhibited by glycerol 3-phosphate (Fig. 5A), which is in accordance with the findings in guinea-pig liver [9]. The effect of Triton X-100 on the acylation of dihydroxyacetone phosphate at $\mathrm{pH} 5.5$ in control fibroblasts and the finding that the enzyme activity is membrane-associated also closely mirror literature data on peroxisomal acyl-CoA : dihydroxyacetone phosphate acyltransferase in other cell types [8,11].

These data, together with the finding that acylCoA : dihydroxyacetone phosphate acyltransferase activity is strongly deficient in cultured skin fibroblasts from patients with the cerebro-hepatorenal (Zellweger) syndrome $[15,20]$ in which peroxisomes are deficient, suggest that the enzyme in cultured skin fibroblasts is primarily localized in peroxisomes.

\section{References}

1 Snyder, F. (1972) Ether Lipids: Chemistry and Biology, Academic Press, New York

2 Horrocks, L.A. and Sharma, M. (1982) in Phospholipids (Hawthorn, J.N. and Ansell, G.B., eds.), pp. 51-94, Elsevier Biomedical Press, Amsterdam

3 Bell, R.M. and Coleman, R.A. (1980) Annu. Rev. Biochem. 49, 459-487

4 Brindley, D.N. and Graham Sturton, R. (1982) in Phospholipids (Hawthorne, H.N. and Ansell, J.B., eds.), pp. 179-213, Elsevier Biomedical Press, Amsterdam

5 Hajra, A.K. (1984) in Ether Phospholipids (Mangold, H.K. and Paltauf, F., eds.), pp. 85-106, Academic Press, New York

6 Hajra, A.K. (1970) Biochem. Biophys. Res. Commun. 39, 1037-1044

7 Jones, C.L. and Hajra, A.K. (1977) Biochem. Biophys. Res. Commun. 76, 1138-1143

8 Hajra, A.K., Burke, C.L. and Jones, C.L. (1979) J. Biol. Chem. 254, 10896-10900

9 Jones, C.L. and Hajra, A.K. (1980) J. Biol. Chem. 255, 8289-8295

10 Hajra, A.K. and Bishop, J.E. (1982) Ann. NY Acad. Sci. $386,170-181$

11 De Clerq, P.E., Haagsman, H.P., van Veldhoven, P., De- 
beer, L.J., van Golde, L.M.G. and Mannaerts, G.P. (1984) J. Biol. Chem. 259, 9064-9075

12 Mackness, M.I. and Connock, M.J. (1985) Comp. Biochem. Physiol. 80B, 161-164

13 Cabot, M.C. and Snyder, F. (1980) Biochim. Biophys. Acta $617,410-418$

14 Schrakamp, G., Schutgens, R.B.H., Wanders, R.J.A., Heymans, H.S.A., Tager, J.M. and Van den Bosch, H. (1985) Biochim. Biophys. Acta 833, 170-174

15 Schutgens, R.B.H., Romeyn, G.J., Wanders, R.J.A., Van den Bosch, H., Schrakamp, G. and Heymans ,H.S.A. (1984) Biochem. Biophys. Res. Commun. 120, 179-184
16 Hajra. A.K. (1968) J. Biol. Chem. 243, 3458-3465

17 Hajra, A.K. and Burke, C.L. (1978) J. Neurochem. 31, 125-134

18 Dodds, P.E., Gurr, M.I. and Brindley, D.N. (1976) Biochem. J. 160, 693-700

19 Bates, E.J. and Saggerson, E.D. (1979) Biochem. J. 182, $751-762$

20 Datta, N.S., Wilson, G.N. and Hajra, A.K. (1984) N. Engl. J. Med. 311, 1080-1083 